\title{
The Effect of Counteranions on the Polymer Steric Structure in the Cationic Polymerization of $\alpha$-Methylstyrene*
}

\author{
Yoshihiko Matsuguma and Toyoki Kunitake \\ Department of Organic Synthesis, Faculty of Engineering, \\ Kyushu University, Fukuoka, 812, Japan.
}

(Received November 16, 1970)

\begin{abstract}
The cationic polymerization of $\alpha$-methylstyrene was carried out at $-78^{\circ} \mathrm{C}$ by using Lewis acids and triphenylmethyl salts as initiator. The polymerization with triphenylmethyl salts was much slower than that with Lewis acids. The triad tacticity data of the polymer determined by NMR spectroscopy fitted the theoretical curve of one parameter (Bovey's $\sigma$ value). The $\sigma$ value, though almost independent of the initiator used in $\mathrm{CH}_{2} \mathrm{Cl}_{2}-\mathrm{CH}_{3} \mathrm{CN}(\sigma \cong 0.04)$, increased with decreasing polarity of polymerization solvents and varied moderately $(0.07-0.34)$ with the initiator in nonpolar solvents. In the case of triphenylmethyl salt initiators, the order of counteranions with increasing $\sigma$ value $\left(\mathrm{SnCl}_{5}-\geq \mathrm{SbCl}_{6}{ }^{-}>\mathrm{AlBr}_{4}{ }^{-}>\mathrm{AlCl}_{4}->\mathrm{BF}_{4}^{-}\right)$was the same as that observed for the isotactic propagation of isobutyl vinyl ether. These results were interpreted within the framework of the cationic propagation scheme proposed by us earlier. The steric influence of counteranions was discussed, and the unusual effect of $\mathrm{SnCl}_{5}^{-}$was considered in connection with its coordination state. The variation of the $\sigma$ value with Lewis acids ( $\mathrm{SnCl}_{4}$ excluded) was much smaller than that with triphenylmethyl salts.

\section{KEY WORDS Cationic Polymerization / Poly ( $\alpha$-methylstyrene) / Steric Structure / Triphenylmethyl Cation / Counteranion / Steric Course / Lewis Acid /}

$\operatorname{Poly}(\alpha$-methylstyrene $)$ is one of the few polymers the steric structure of which can be determined quantitatively. The variation of the steric structure of poly( $\alpha$-methylstyrene) with polymerization conditions has been investigated and its implication discussed by Ohsumi, et al. ${ }^{1}$ Previously we also investigated polymerizations of $\alpha$-methylstyrene with several Lewis acids in connection with our proposal on the steric course of the cationic propagation, and found that the steric course of propagation was affected by the Lewis acid used. ${ }^{2}$ In the case of the cationic polymerization of isobutyl vinyl ether with triphenylmethyl salts, the steric structure of the resulting polymer was correlated mainly with the size of the counteranion. ${ }^{3}$ We therefore became interested to learn how the counteranion would affect the steric structure of poly( $\alpha$-methylstyrene). In this paper we

* This is contribution No. 227 from this department and Part III in the series "Mechanism of Cationic Polymerizations.", describe cationic polymerizations of $\alpha$-methylstyrene with several triphenylmethyl salts and Lewis acids, and discuss the influence of the counteranion on the steric course of propagation.

\section{EXPERIMENTAL}

\section{Materials}

$\alpha$-Methylstyrene was washed with dilute aqueous alkali and with water, dried over $\mathrm{CaCl}_{2}$, and distilled at reduced pressure under nitrogen with the use of a Vigreux column. The purity was confirmed by gas chromatography. The purified monomer was again distilled before use from $\mathrm{CaH}_{2}$. Solvents were purified by conventional methods. The preparation and characterization of triphenylmethyl salts were described previously. ${ }^{3} \quad \mathrm{BF}_{3} \mathrm{OEt}_{2}, \mathrm{SbCl}_{5}$, and $\mathrm{SnCl}_{4}$ were purified by distillation. $\mathrm{AlCl}_{3}$ was sublimed under nitrogen from its mixture with $\mathrm{NaCl}$ and $\mathrm{Al}$ powders. 


\section{Y. Matsuguma and T. Kunitake}

\section{Polymerization}

The polymerization with triphenylmethyl salts was conducted in glass-stoppered test tubes with side-arms for the nitrogen inlet. When polymerizations were carried out in $\mathrm{CH}_{2} \mathrm{Cl}_{2}-$ methylcyclohexane $(\mathrm{MCH})$ mixtures, a given amount of initiator solution in $\mathrm{CH}_{2} \mathrm{Cl}_{2}$ was mixed with a necessary amount of $\mathrm{MCH}$ and cooled to $-78^{\circ} \mathrm{C}$. The total volume of solvents was usually $60 \mathrm{~m} l$. Five $\mathrm{m} l$ of monomer were then added under nitrogen while stirring. In the case of polymerizations in $\mathrm{CH}_{2} \mathrm{Cl}_{2}$ solvent, $1 \mathrm{~m} l$ of an initiator solution in $\mathrm{CH}_{2} \mathrm{Cl}_{2}$ was added to a mixture of $5 \mathrm{~m} l$ of monomer and $49 \mathrm{~m} l$ of $\mathrm{CH}_{2} \mathrm{Cl}_{2}$ at $-78^{\circ} \mathrm{C}$. One $\mathrm{m} l$ of monomer, $1 \mathrm{~m} l$ of an initiator solution and $9 \mathrm{~m} l$ of solvent were used in polymerizations in $\mathrm{CH}_{2} \mathrm{Cl}_{2}-\mathrm{CH}_{3} \mathrm{CN}$ mixtures. The polymerization was terminated by adding methanol, and the mixture was poured into excess methanol. Upon centrifugation and washing, the polymer was dried in vacuo and weighed. The sample used for NMR measurements was reprecipitated from benzene and methanol.

The polymerization with Lewis acids was carried out in a similar manner. Catalyst solutions were added to mixtures of monomer and solvents at $-78^{\circ} \mathrm{C}$. The work-up was the same.

\section{Miscellaneous}

NMR spectra were obtained with a Varian A60 instrument is chlorobenzene at $120^{\circ} \mathrm{C}$. The polymer concentration was $10 \%(\mathrm{w} / \mathrm{v})$. The stereochemistry of the polymer was determined by the cut-and-weigh method of the relative area of the three methyl signals in the NMR spectrum. Viscosities were measured in benzene at $30^{\circ} \mathrm{C}$.

\section{RESULTS AND DISCUSSION}

\section{Polymerization}

The polymerization data of $\alpha$-methylstyrene with triphenylmethyl salts are given in Table I.

Table I. Polymerization of $\alpha$-methylstyrene with triphenylmethyl salts at $-78^{\circ} \mathrm{C}$

\begin{tabular}{|c|c|c|c|c|c|c|c|c|}
\hline \multirow{2}{*}{$\begin{array}{c}\text { No. } \\
1\end{array}$} & \multicolumn{2}{|c|}{$\begin{array}{l}\text { Initiatora, } \\
\mathrm{mol} / l \times 10^{3}\end{array}$} & \multirow{2}{*}{$\begin{array}{c}\begin{array}{c}\text { Monomer, } \\
\mathrm{mol} / l\end{array} \\
0.60\end{array}$} & \multirow{2}{*}{$\frac{\text { Solvent }^{b}}{\mathrm{I}}$} & \multirow{2}{*}{$\begin{array}{c}\begin{array}{c}\text { Polymeri- } \\
\text { zation } \\
\text { time, hr }\end{array} \\
20\end{array}$} & \multirow{2}{*}{$\begin{array}{c}\begin{array}{c}\text { Conversion, } \\
\%\end{array} \\
46.4\end{array}$} & \multirow{2}{*}{$\begin{array}{l}\begin{array}{l}{[\eta], \mathrm{c}} \\
\mathrm{d} l / \mathrm{g}\end{array} \\
0.532\end{array}$} & \multirow{2}{*}{$\begin{array}{c}\sigma^{\mathrm{d}} \\
0.233\end{array}$} \\
\hline & $\mathrm{Ph}_{3} \mathrm{C}^{+} \mathrm{AlCl}_{4^{-}}^{-}$ & 4.8 & & & & & & \\
\hline 2 & $\mathrm{Ph}_{3} \mathrm{C}^{+} \mathrm{SnCl}_{5}^{-}$ & 9.0 & 0.60 & I & 489 & 1.1 & - & 0.346 \\
\hline 3 & $\mathrm{Ph}_{3} \mathrm{C}^{+} \mathrm{AlBr}_{4}^{-}$ & 8.3 & 0.65 & II & 67.5 & 12.4 & 0.983 & 0.099 \\
\hline 4 & $\mathrm{Ph}_{3} \mathrm{C}^{+} \mathrm{AlCl}_{4}^{--}$ & 7.5 & 0.65 & II & 2 & 75.0 & 0.700 & 0.080 \\
\hline 5 & $\mathrm{Ph}_{3} \mathrm{C}^{+} \mathrm{BF}_{4}^{-}$ & 5.5 & 0.71 & $\mathrm{II}^{\prime}$ & 75 & 6.3 & - & 0.068 \\
\hline 6 & $\mathrm{Ph}_{3} \mathrm{C}^{+} \mathrm{BF}_{4}^{-}$ & 6.2 & 0.65 & II & 336 & 3.9 & 0.216 & 0.074 \\
\hline 7 & $\mathrm{Ph}_{3} \mathrm{C}^{+} \mathrm{SbCl}_{\hat{6}^{-}}^{-}$ & 3.9 & 0.65 & II & 384 & 1.2 & 0.285 & 0.127 \\
\hline 8 & $\mathrm{Ph}_{3} \mathrm{C}^{+} \mathrm{SnCl}_{5}^{-}$ & 6.5 & 0.71 & $\mathrm{II}^{\prime}$ & 75 & 49.8 & - & 0.130 \\
\hline 9 & $\mathrm{Ph}_{3} \mathrm{C}^{+} \mathrm{SnCl}_{5}^{-}$ & 9.0 & 0.65 & II & 190 & 27.2 & 0.516 & 0.135 \\
\hline 10 & $\mathrm{Ph}_{3} \mathrm{C}^{+} \mathrm{AlBr}_{4}^{-}$ & 1.8 & 0.71 & III & 0.5 & 5.8 & 1.72 & 0.056 \\
\hline 11 & $\mathrm{Ph}_{3} \mathrm{C}^{+} \mathrm{AlCl}_{4}^{-}$ & 1.8 & 0.71 & III & 0.3 & 7.4 & 2.39 & 0.056 \\
\hline 12 & $\mathrm{Ph}_{3} \mathrm{C}^{+} \mathrm{BF}_{4}^{-}$ & 3.5 & 0.71 & III & 71 & 8.0 & 0.183 & 0.066 \\
\hline 13 & $\mathrm{Ph}_{3} \mathrm{C}^{+} \mathrm{SbCl}_{6}{ }^{-}$ & 1.8 & 0.71 & III & 18 & 12.8 & 0.618 & 0.084 \\
\hline 14 & $\mathrm{Ph}_{3} \mathrm{C}^{+} \mathrm{SnCl}_{5}^{-}$ & 2.5 & 0.71 & III & 24 & 3.6 & 0.164 & 0.074 \\
\hline 15 & $\mathrm{Ph}_{3} \mathrm{C}^{+} \mathrm{AlCl}_{4}^{-}$ & 10 & 0.71 & IV & 96 & 6.6 & - & 0.045 \\
\hline 16 & $\mathrm{Ph}_{3} \mathrm{C}^{+} \mathrm{BF}_{4}^{-}$ & 1.9 & 0.71 & IV & 96 & 56.2 & 0.272 & 0.042 \\
\hline 17 & $\mathrm{Ph}_{3} \mathrm{C}^{+} \mathrm{SbCl}_{6}^{-}$ & 4.9 & 0.71 & IV & 96 & 21.7 & - & 0.045 \\
\hline 18 & $\mathrm{Ph}_{3} \mathrm{C}^{+} \mathrm{SnCl}_{5}^{-}$ & 12 & 0.71 & IV & 96 & 23.9 & - & 0.041 \\
\hline
\end{tabular}

a Initiator not completely soluble in solvents $\mathrm{I}$ and II.

b Solvent $\mathrm{I}$, methylcyclohexane $(\mathrm{MCH})-\mathrm{CH}_{2} \mathrm{Cl}_{2}$ (10:2 by volume); II, $\mathrm{MCH}-\mathrm{CH}_{2} \mathrm{Cl}_{2}$ (8:3 by volume); II', $\mathrm{MCH}-\mathrm{CH}_{2} \mathrm{Cl}_{2}$ (7:3 by volume); III, $\mathrm{CH}_{2} \mathrm{Cl}_{2} ; \mathrm{IV}, \mathrm{CH}_{2} \mathrm{Cl}_{2}-\mathrm{CH}_{3} \mathrm{CN}$ (7:3 by volume).

c Determined in benzene at $30^{\circ} \mathrm{C}$.

d Calculated from eq 1 . 
The polymerization was generally slow. It was particularly slow in methylcyclohexane (MCH)$\mathrm{CH}_{2} \mathrm{Cl}_{2}$ (10:2 by volume) media and, therefore, the number of initiators used in this solvent was limited. The polymer precipitated during polymerization in $\mathrm{CH}_{2} \mathrm{Cl}_{2}-\mathrm{CH}_{3} \mathrm{CN}$ and $\mathrm{MCH}-$ $\mathrm{CH}_{2} \mathrm{Cl}_{2}$ solvents. In $\mathrm{CH}_{2} \mathrm{Cl}_{2}$ gel-like polymers precipitated partially. The triphenylmethyl salts used were only partially soluble in $\mathrm{MCH}-$ $\mathrm{CH}_{2} \mathrm{Cl}_{2}$ mixtures, and, therefore, the initiator concentrations given in Table $\mathrm{I}$ are not accurate for these solvents.

The polymerization of styrene and $\alpha$-methylstyrene with triphenylmethyl cation as initiator has been studied by several groups, ${ }^{4-6}$ and it was generally agreed that the initiation step was the addition of the triphenylmethyl cation to monomer molecules. The salt anion would then become the counteranion in the growing species.

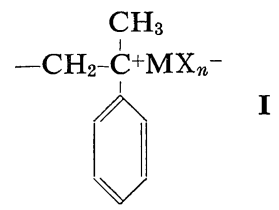

The polymerization with some Lewis acids is summarized in Table II. Except for $\mathrm{AlCl}_{3}$ the catalysts used were soluble in polymerization mixtures. The polymerization was much faster with Lewis acids, but $\mathrm{SnCl}_{4}-\mathrm{H}_{2} \mathrm{O}$ was less effective.

The Steric Structure of the Polymer Obtained with Triphenylmethyl Initiators

The steric structure of poly ( $\alpha$-methylstyrene) can be determined from the relative area of the three methyl signals in the NMR spectrum. The assignment of these signals has been a subject of considerable controversy. Recently, Ramey, et al., ${ }^{7}$ assigned the three methyl peaks to the isotactic, heterotactic and syndiotactic triads in the order of increasing magnetic fields, on the basis of the analysis of the methyl and methylene peaks of $220-\mathrm{MHz}$ spectra. This assignment, being the one that we adopted in the previous study, appears most satisfactory and is, therefore, employed in the present study.

The reproducibility of tacticity determination (the fraction of the syndiotactic triad, $T_{s}$ ) can be considered to be within $\pm 0.5 \%$. For instance, the syndiotactic fraction was 86.8 and $85.8 \%$ with $\mathrm{Ph}_{3} \mathrm{C}^{+} \mathrm{BF}_{4}^{-}$initiator in $\mathrm{MCH}-$ $\mathrm{CH}_{2} \mathrm{Cl}_{2}$ (Run no. 5 and 6, Table I), and 75.7 and $74.9 \%$ with $\mathrm{Ph}_{3} \mathrm{C}^{+} \mathrm{SnCl}_{5}{ }^{-}$initiator in $\mathrm{MCH}-$ $\mathrm{CH}_{2} \mathrm{Cl}_{2}$ (Run no. 8 and 9, Table I). The signal-to-noise ratio of the spectrum was much

Table II. Polymerization of $\alpha$-methylstyrene with Lewis acids at $-78^{\circ} \mathrm{C}$

\begin{tabular}{|c|c|c|c|c|c|c|c|c|}
\hline \multirow{2}{*}{$\begin{array}{c}\text { No. } \\
1\end{array}$} & \multicolumn{2}{|l|}{$\begin{array}{c}\text { Catalyst } \\
\times 10^{3}, \mathrm{~mol} / l\end{array}$} & \multirow{2}{*}{$\begin{array}{c}\begin{array}{c}\text { Monomer, } \\
\mathrm{mol} / l\end{array} \\
0.60\end{array}$} & \multirow{2}{*}{$\begin{array}{c}\text { Solvent } \\
\text { I }\end{array}$} & \multirow{2}{*}{$\begin{array}{c}\text { Polymeri- } \\
\text { zation } \\
\text { time, min } \\
10\end{array}$} & \multirow{2}{*}{$\begin{array}{c}\begin{array}{c}\text { Conversion, } \\
\%\end{array} \\
77.6\end{array}$} & \multirow{2}{*}{$\begin{array}{l}{[\eta]^{\mathbf{b}}} \\
-\end{array}$} & \multirow{2}{*}{$\begin{array}{c}\sigma^{\mathrm{c}} \\
0.080\end{array}$} \\
\hline & $\mathrm{AlCl}_{3} \mathrm{~d}$ & a. 3 & & & & & & \\
\hline 2 & $\mathrm{BF}_{3} \mathrm{OEt}_{2}$ & 3.8 & 0.60 & I & $18 \mathrm{hr}$ & 38.7 & 0.643 & 0.101 \\
\hline 3 & $\mathrm{SbCl}_{5}$ & 1.8 & 0.60 & I & 10 & 41.7 & - & 0.086 \\
\hline 4 & $\mathrm{SnCl}_{4}$ & 4.3 & 0.60 & I & 13 & 6.9 & - & 0.215 \\
\hline 5 & $\mathrm{SnCl}_{4}-\mathrm{TCA}(1: 1)$ & 2.0 & 0.60 & I & 20 & 11.4 & - & 0.153 \\
\hline 6 & $\mathrm{SnCl}_{4}-\mathrm{H}_{2} \mathrm{O}(1: 1)$ & 2.0 & 0.60 & I & $76 \mathrm{hr}$ & 6.1 & - & 0.172 \\
\hline 7 & $\mathrm{AlCl}_{3}{ }^{\mathrm{d}} \quad c a$. & a. 3 & 0.65 & II & 10 & 93.6 & - & 0.066 \\
\hline 8 & $\mathrm{BF}_{3} \mathrm{OEt}_{2}$ & 4.2 & 0.65 & II & 180 & 14.5 & 0.691 & 0.065 \\
\hline 9 & $\mathrm{SbCl}_{5}$ & 1.9 & 0.65 & II & 10 & 56.8 & - & 0.069 \\
\hline 10 & $\mathrm{SnCl}_{4}$ & 4.7 & 0.65 & II & 10 & 41.2 & - & 0.112 \\
\hline 11 & $\mathrm{BF}_{3} \mathrm{OEt}_{2}$ & 4.5 & 0.71 & III & 120 & 27.6 & 0.780 & 0.053 \\
\hline 12 & $\mathrm{BF}_{3} \mathrm{OEt}_{2}$ & 4.5 & 0.71 & IV & $18 \mathrm{hr}$ & 10.7 & - & 0.037 \\
\hline
\end{tabular}

a Solvent I, methylcyclohexane ( $\mathrm{MCH})-\mathrm{CH}_{2} \mathrm{Cl}_{2}$ (10:2 by volume); II, $\mathrm{MCH}-\mathrm{CH}_{2} \mathrm{Cl}_{2}$ (8:3 by volume); III, $\mathrm{CH}_{2} \mathrm{Cl}_{2} ; \mathrm{IV}, \mathrm{CH}_{2} \mathrm{Cl}_{2}-\mathrm{CH}_{3} \mathrm{CN}$ (7:3 by volume).

b Determined in benzene at $30^{\circ} \mathrm{C}$.

c Calculated from eq 1 .

d Not completely soluble. 


\section{Y. Matsuguma and T. Kunitake}

better in the present measurements than in those of the previous ones. ${ }^{2}$ The experimental error in $T_{s}$ was estimated to be $\pm 2 \%$ in the latter case.

The probability of the isotactic propagation $\sigma$ as defined by Bovey is calculated from $T_{s}$ by the following equation

$$
T_{s}=(1-\sigma)^{2}
$$

Previously it was shown that the variation of the steric structure of poly $(\alpha$-methylstyrene) could be described by a single parameter $\sigma .^{8,9}$ This assumption is also valid for the tacticity data of the present investigation as shown in Figure 1. The Bovey plots closely fit the

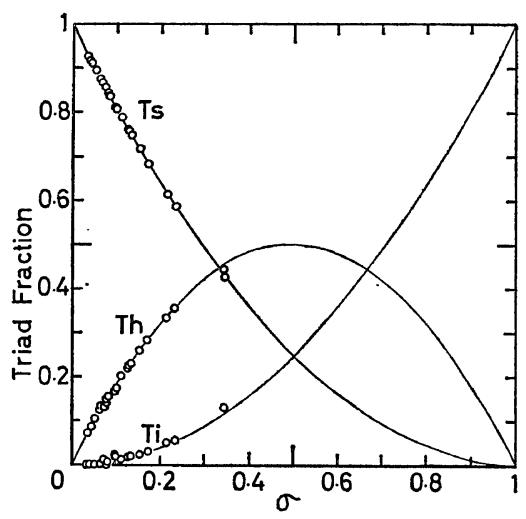

Figure 1. Bovey plots: $T_{s}$, syndiotactic; $T_{h}$, heterotatic; $T_{i}$, isotactic triad.

theoretical curve of one parameter $\sigma$, thus precluding the presence of the penultimate effect. The variation of $\sigma$ with initiators and polymerization solvents is shown in Figure 2. The solvent systems are arranged in the order of increasing polarity in the abscissa. It is to be noted that the $\sigma$ values are small. Therefore, syndiotactic propagation is predominant in all the systems. The $\sigma$ value increased with decreasing polarity of the solvent. The variation of the $\sigma$ value with counteranions was greatest in the least polar solvent and the difference diminished as the polarity of the polymerization medium increased. In $\mathrm{CH}_{2} \mathrm{Cl}_{2}-$ $\mathrm{CH}_{3} \mathrm{CN}$ solvent the $\sigma$ value was independent of the counteranion, indicating that the growing ion-pair was too loose for the counteranion to

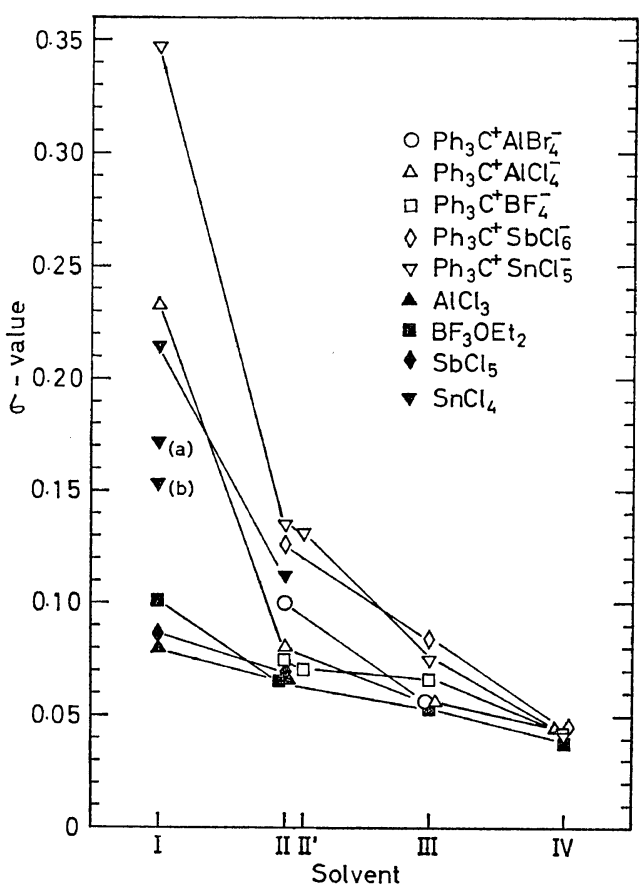

Figure 2. Variation of the $\sigma$ value with polymerization conditions: solvent I, $\mathrm{MCH}-\mathrm{CH}_{2} \mathrm{Cl}_{2}$ (10:2); solvent $\mathrm{II}, \mathrm{MCH}-\mathrm{CH}_{2} \mathrm{Cl}_{2}$ (8:3); solvent $\mathrm{II}^{\prime}, \mathrm{MCH}-$ $\mathrm{CH}_{2} \mathrm{Cl}_{2}$ (7:3); solvent III, $\mathrm{CH}_{2} \mathrm{Cl}_{2}$; solvent IV, $\mathrm{CH}_{2} \mathrm{Cl}_{2}-\mathrm{CH}_{3} \mathrm{CN}$ (7:3); (a), $\mathrm{SnCl}_{4}-\mathrm{H}_{2} \mathrm{O}$ catalyst; (b), $\mathrm{SnCl}_{4}$-trichloroacetic acid (TCA) catalyst.

affect the steric course of propagation.

According to the model of the steric course of propagation proposed earlier, ${ }^{2}$ the most stable conformation of the growing $\alpha$-methylstyrene segment is assumed to be the one shown by II. Insertion of a monomer molecule at the front side gives rise to a syndiotactic placement and insertion at the back side an isotactic placement.

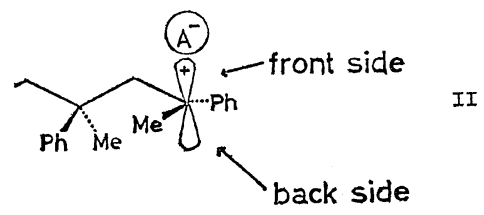

As explained previously, a syndiotactic placement at the front side is favored for $\alpha$-methylstyrene, because the $\alpha$-carbon is disubstituted and the back-side attack is less favorable due to enhanced steric hindrance of the penultimate side chains. Nevertheless, the 
back-side attack to give an isotactic placement will be facilitated when a tightly bound counteranion interferes with the front-side attack.

The $\sigma$ value increased in $\mathrm{MCH}-\mathrm{CH}_{2} \mathrm{Cl}_{2}(8 / 3)$ solvent in the following order of the counteranion.

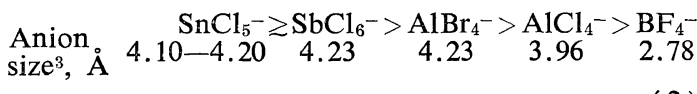

Thus isotacticity of $\operatorname{poly}(\alpha$-methylstyrene $)$ increased mainly with increasing sizes of the counteranion in this solvent, except for $\mathrm{SnCl}_{5}^{-}$. Interestingly, this order is the same as that of increasing isotacticity in the cationic polymerization of isobutyl vinyl ether. ${ }^{3}$ Therefore, the role of the counteranion in affecting the steric course appears to be the same with these two monomers in spite of their different side chains. This is consistent with our proposed scheme, since none of the specific interactions of monomer substituents with counteranions was required for determining the steric course in this scheme. The steric hindrance of the counteranion is seemingly more influential than the coulombic interaction of the ions in determining the site of monomer attack in both systems.

The $\mathrm{SnCl}_{5}{ }^{-}$anion gave a larger amount of the isotactic unit than would be expected from its size. The coordination number of this anion is five, in contrast with the coordination numbers of four and six in other anions which correspond to the tetrahedral and octahedral structures, respectively.

It is known that the structure of pentacoordinate compounds is generally nonrigid, ${ }^{10}$ and one of the possible configurations-trigonal bipyramid-may readily convert to the other configuration-tetragonal pyramid. This structural characteristics can give rise to an asymmetrical $\mathrm{SnCl}_{5}{ }^{-}$anion, and its effect could be different from what is expected from its size alone.

The Steric Structure of the Polymer Obtained with Lewis Acids

The variation of the $\sigma$ values of the polymer obtained with several Lewis acids is also shown in Figure 2. Except for $\mathrm{SnCl}_{4}$ polymers, the $\sigma$ values were much smaller than those of the polymers obtained with triphenylmethyl initia- tors. The order of Lewis acids with increasing $\sigma$ values (in $10: 2 \mathrm{MCH}-\mathrm{CH}_{2} \mathrm{Cl}_{2}$ ) was

$$
\mathrm{SnCl}_{4}>\mathrm{BF}_{3} \mathrm{OEt}_{2}>\mathrm{SbCl}_{5} \gtrsim \mathrm{AlCl}_{3}
$$

This order agrees with that previously observed in $\mathrm{MCH}-$ toluene solvents: $\mathrm{SnCl}_{4}>\mathrm{BF}_{3} \mathrm{OEt}_{2} \geq$ $\mathrm{TiCl}_{4}>\mathrm{AlCl}_{3}{ }^{2}$.

It is evident from Figure 2 that the influence of Lewis acid catalysts on $\sigma$ is small. In fact, almost the same value was obtained for $\mathrm{BF}_{3} \mathrm{OEt}_{2}$, $\mathrm{SbCl}_{5}$, and $\mathrm{AlCl}_{3}$ in $8: 3 \mathrm{MCH}-\mathrm{CH}_{2} \mathrm{Cl}_{2}$. Thus it is suggested that the interaction of the counteranions derived from these Lewis acids with the propagating cation is weak, so far as the steric course is concerned.

The different effects of triphenylmethyl salts and the corresponding Lewis acids are noteworthy. The structure of the counteranions derived from Lewis acids may be more complex than expected from simple coordination of cocatalysts.

The peculiarity of $\mathrm{SnCl}_{4}$ compared with other Lewis acids is evident in Figure 2. An explanation similar to that given for $\mathrm{SnCl}_{5}{ }^{-}$may again be applicable. Interestingly, addition of equimolar amounts of cocatalysts $\left(\mathrm{H}_{2} \mathrm{O}\right.$ or trichloroacetic acid) to $\mathrm{SnCl}_{4}$ resulted in decreased $\sigma$ values.

It is probable that, among many facets of the counteranion effect, the steric effect is especially important in determining the steric course of propagation. The reactivity of growing ion-pairs may be influenced more strongly by other facets of the counteranion effect. In this connection we are now carrying out copolymerization, and other reactions related to polymerization, using triphenylmethyl salts.

Acknowledgement. We are deeply grateful to Prof. Chuji Aso head of our research group, for his constant encouragement and advice.

\section{REFERENCES}

1. Y. Ohsumi, T. Higashimura, and S. Okumura, J. Polym. Sci., Part A-1, 4, 923 (1966).

2. T. Kunitake and C. Aso, ibid., Part $A-1,8$, 665 (1970).

3. T. Kunitake, T. Matsuguma, and C. Aso, Polymer J., 2, 345 (1971).

4. T. G. Bonner, J. M. Clayton, and G. Williams, 


\section{Y. Matsuguma and T. Kunitake}

J. Chem. Soc., 391 (1964).

5. M.S. Sambhi and F. E. Treloar, J. Polym. Sci., Part B, 3, 445 (1965); M. S. Sambhi, Macromolecules, 3, 351 (1970).

6. T. Higashimura, T. Fukushima, and S. Okamura, J. Macromol. Sci., A1, 683 (1967).

7. K. C. Ramey, G. L. Statton, and W. C. Jankow- ski, J. Polym. Sci., Part B, 7, 639 (1969).

8. S. Brownstein, S. Bywater, and D. J. Worsfold, Makromol. Chem., 48, 127 (1961).

9. Y. Ohsumi, T. Higashimura, and S. Okamura, J. Polym. Sci., Part A, 3, 3729 (1965).

10. E. L. Muetterties and R. A. Schunn, Quart. Rev. (London), 20, 245 (1966). 